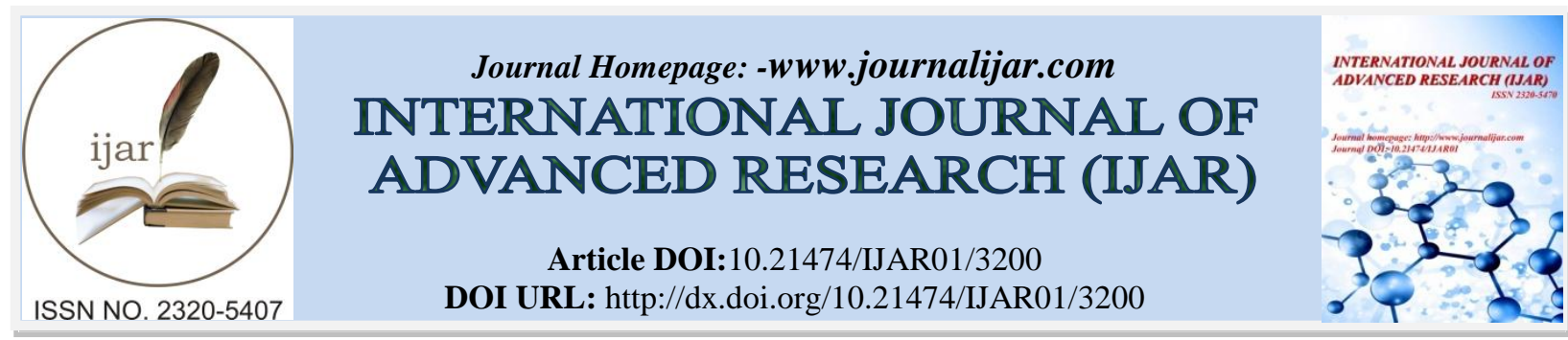

RESEARCH ARTICLE

\title{
PRELIMINARY PARAMETERS OF HEMATOLOGIC VALUES IN BARBARY SHEEP (AMMOTRAGUS LERVIA PALLAS, 1777).
}

\author{
Daniela Mello Vianna Ferrer ${ }^{1}$, Carlos Henrique Pizarro Borges ${ }^{2}$, Vera Lucia de Oliveira ${ }^{3}$ and Denise de Mello \\ Bobany*1. \\ 1. Unifeso- Centro Universitario Serra dos Orgaos- Teresopolis-Rio de Janeiro-Brasil. \\ 2. Ministerio da Agricultura, Pecuaria e Abastecimento, Secretaria de DefesaAgropecuaria,Departamento de \\ Saúde Animal- Brasil. \\ 3. Fundacao Rio-Zoo-Brasil.
}

\section{Manuscript Info}

Manuscript History

Received: 18 December 2016

Final Accepted: 04 January 2017

Published: February 2017

Key words:-

Ammotraguslervia, bovidae, hematological, Aoudad and Barbary Sheep.

\section{Abstract}

The deficiency of information and updates related to normal haematological and biochemical parameters study of certain species, such as the case of Ammotraguslervia species (Barbary sheep), generates the need for further research in this area. Therefore, in this work were used five animals of the Ammotraguslervia species, one male and four females, to the preliminary study of its hematological parameters. All quantitative and qualitative determinations were established by conventional techniques, and used the same techniques of domestic ruminants. Haematological values obtained for the average Ammotraguslervia species were: RBC 13.17 x $10^{6} / \mathrm{mm}^{3} ; 14.02$ hemoglobin g/100 ml; PCV 42.20\%; MCV 32.38 fl; MCH 10.72 pg; MCHC 33.18\%; WBC $9.92 \times 10^{3} / \mathrm{mm}^{3}$; Basophils 0\%; Eosinophils 3\%; Band Neutrophils 3\%; Segmented Neutrophils 66\%; Lymphocytes $27 \%$; Monocytes $1 \%$. In the statistical analysis was determined just the average of the variables, just like standard deviation and confidence intervals, due to the small number of individuals and of inequality between the number of males and females. Standard techniques used in the preparation of haematological exams for the domestic ruminants are effective for Ammotraguslervia species. Haematological values obtained for the Ammotraguslervia species exhibit a variability regarding the data of hematological values described in the literature. The discoid biconcave format and the smaller size of the red blood cells observed in this study for the Ammotraguslervia species are equal to the shape and size of the cells described in the literature for the same species.

\section{Introduction:-}

Currently, the use of laboratory examinations in veterinary medicine complements the clinical work, as it often can facilitate the observation of some physiopathological changes arising from any illness. The correct evaluation of the physiological state of an animal, the extent of the damage to the tissues and organs and the response of the defense 
mechanism of the patient depends directly from the appropriate analysis of the results of laboratory tests, physical examination and clinical history (Coles, 1984; Tibbo et al., 2004).

In the clinical pathology of wild animals field, few studies have been developed, mainly related to hematological and biochemical normal parameters of certain species. There is deficiency of information and many of the available studies in the literature are old or the variables used in this studies, have changed a lot since the preparation of same parameters, as climate, geographic distribution, eating habits and destruction of natural habitats. According to Peinado et al. (1999) there are several studies on the Hematology of Artiodactylas, but these are very incomplete and there are still several gaps in this area.

The species Ammotraguslervia (Barbary sheep, Aoudad) of the order Artiodactyla is of African origin, which occurs in Highlands in desert areas and semi-deserts areas of Morocco and Western Sahara to the Egypt and the Sudan (Wilson and Reeder, 2005), is small, with a frizzy hair and both sexes feature a large fringe on throat and chest region extending to the lower parts of the forelimbs. Its coloration varies between the brown sand color, being the lowest parts of moderately clear coloring, features prominent horns, strong and full of pleats, and the horns of adult males are larger and more prominent than the females (Casinello, 1998; Nowak, 1999).

The Ammotraguslervia is the wild sheep more common captive-breed, as it is the only one that adapts quickly (Tumbleson et al., 1970; Wallach and Boever, 1983; Jessup, 1999). In addition, there is a great ecological interest in this species, since many of these specimenswere removed from their natural habitats and transferred mostly to the Americas with the aim of its use for the practice of sport hunting (Boever, 1986; Nowak, 1999).

The great interesting in the study of Ammotraguslervia species is due to the fact that this is considered at risk of extinction, the category of vulnerable species (VU C1) as the IUCN Red List of Threatened Species classification (IUCN, 2016), as well as in Appendix 2 of CITES (Convention on International Trade in Endangered Species of Wild Fauna and Flora) (Shackleton, 1997;Casinello, 1998; Nowak, 1999; CITES, 2016).

According to Tumbleson et al. (1970) the Ammotraguslervia species has great tendency to the natural occurrence of atherosclerosis and the study of their values of serum biochemical and haematological parameters can help establish this species as model animal for studies of the disease.

This work aims to contribute with preliminary standards haematological parameters for Ammotraguslervia species in order to decrease the existing shortcomings in the literature, improving knowledge of data in the area of wild ruminants.

\section{Material and Methods:-}

It was studied five animals of the Ammotraguslervia species, from the livestock of Rio Zoo Foundation/R.J., one male and four females, clinically healthy.

The females were marked with numbered rings in his ears, and the male did not present any markup. This work was not taken into consideration the age of the animals.

\section{Hemogram:-}

From each animal was taken $3 \mathrm{ml}$ of blood sample by external jugular vein puncture using a $5 \mathrm{ml}$ disposable syringe (BD brand) and a disposable needle (25x7) as recommended by Peinado et al. (1999), Tumbleson et al. (1970), Wallach and Boever (1983), Kitchen (1986) and Fowler (2003).

Immediately after venipuncture were made three smears with the blood sample, without any contact with the anticoagulant, and later the blood was transferred to a tube containing EDTA (Vacutainer EDTA 26 BD brand). After the homogenization of the sample with the anticoagulant and air-drying of smears, with their respective IDs, the samples were immediately processed in own laboratory of Rio-Zoo Foundation.

All of the following quantitative and qualitative determinations were established by conventional techniques according to Schalm et al. (1975):

a) Erythrogram: Red blood cell (RBC - hemocytometer), Hemoglobin concentration (Hb - cianometahemoglobin spectrophotometry), Packed cell volume (PCV -microhematocrit). Mean corpuscular volume (MCV), Mean 
corpuscular hemoglobin concentration (MCHC), and Mean corpuscular hemoglobin $(\mathrm{MCH})$ were calculated according to the following formula:

$$
\begin{array}{ll}
\mathrm{MCV} & =\mathrm{PCV} \times 10 ; \mathrm{MCH}=\mathrm{Hb} \times 10 \text { e } \mathrm{MCHC}=\mathrm{Hb} \times 10 . \\
\mathrm{RBC} & \mathrm{RBC}
\end{array}
$$

b) Leukogram: white blood cell count (WBC - hemocytometer) and differential leukocyte count, as well as MayGrünwald-Giemsa stain blood smears (MGG) for qualitative analysis of red and white cells (Rullier, 1968).

On statistical analysis of hematological values of the five animals of the Ammotraguslervia species was determined only the average of the variables studied, as well as the values of standard deviation and confidence interval (lower and upper limit), due to the small number of individuals and of inequality between the number of males and females, which made it impossible for a more specific statistical survey on the difference between these averages.

\section{Results:-}

It was not necessary the use of tranquilizers on animals of Rio-Zoo Found by the fact that, in addition to these animals are already accustomed to the daily management of their handlers, the speed of the process and the low nuisance which is caused to animals (Fig. 1), offering a final result of the analysis of the material without interference from medication.

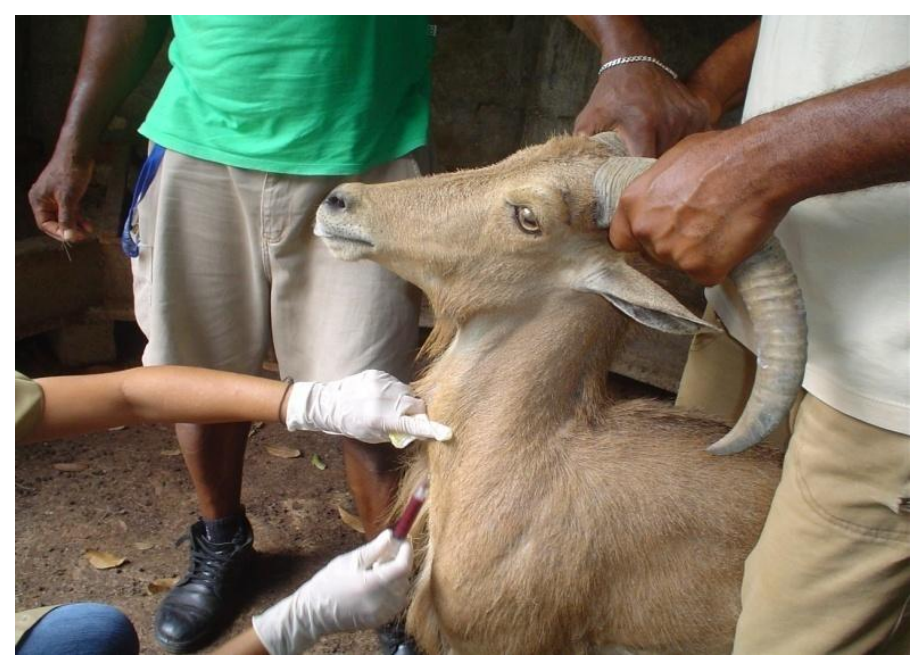

Fig. 1:- Mechanical restraint of a specimen of the Ammotraguslervia species blood collection

In relation to the shape and size of the blood cells of the Ammotraguslervia species, it was observed that the red blood cells present a discoid biconcave format in the proportion sizes as the domestic goats and sheeps cells.

The individualized results obtained from peripheral blood samples of the five animals of the Ammotraguslervia species (Barbary sheep) are described in tables 1 and 2, respectively.

Table 1:-Erythrogram values inAmmotraguslerviaspecies $(\mathrm{n}=05)$

\begin{tabular}{|l|c|c|c|c|c|c|c|c|}
\hline Animal & Sex & Date & RBC & Hb & PCV & MCV & MCH & MCHC \\
\hline $\mathbf{N}^{\mathbf{0}} \mathbf{1}$ & $\mathrm{F}$ & $14 / 12 / 06$ & 16,45 & 15,6 & 47 & 28,5 & 9,4 & 33,1 \\
\hline $\mathbf{N}^{\mathbf{0}} \mathbf{2}$ & $\mathrm{F}$ & $14 / 12 / 06$ & 11,71 & 16,6 & 50 & 42,6 & 14,1 & 33,2 \\
\hline $\mathbf{N}^{\mathbf{0}} \mathbf{3}$ & $\mathrm{F}$ & $14 / 12 / 06$ & 14,53 & 13,6 & 41 & 28,2 & 9,3 & 33,1 \\
\hline $\mathbf{N}^{\mathbf{0}} \mathbf{4}$ & $\mathrm{F}$ & $14 / 12 / 06$ & 12,21 & 14,3 & 43 & 35,2 & 11,7 & 33,2 \\
\hline $\mathbf{N}^{\mathbf{0}} \mathbf{5}$ & $\mathrm{M}$ & $14 / 12 / 06$ & 10,94 & 10,0 & 30 & 27,4 & 9,1 & 33,3 \\
\hline RBC Red Blood Cells x 10\% $/ \mathrm{mm}^{3}$ & \multicolumn{7}{|l|}{ MCV Mean Corpuscular Volume fl } \\
\hline
\end{tabular}


Table 2:-Leukogram values in Ammotraguslervia species $(\mathrm{n}=05)$

\begin{tabular}{|c|c|l|c|c|c|c|c|c|c|}
\hline Animal & Sex & Date & WBC & Bas & Eos & Band & Seg & Lym & Mn \\
\hline $\mathbf{N}^{\mathbf{0}} \mathbf{1}$ & $\mathrm{F}$ & $14 / 12 / / 06$ & 7,20 & 0 & $7(504)$ & 0 & $69(4968)$ & $24(1728)$ & 0 \\
\hline $\mathbf{N}^{\mathbf{0}} \mathbf{2}$ & $\mathrm{F}$ & $14 / 12 / 06$ & 12,70 & 0 & $3(381)$ & $\begin{array}{c}2 \\
(254)\end{array}$ & $80(10160)$ & $13(1651)$ & $2(254)$ \\
\hline $\mathbf{N}^{\mathbf{0}} \mathbf{3}$ & $\mathrm{F}$ & $14 / 12 / 06$ & 11,50 & 0 & $4(460)$ & $\begin{array}{c}1 \\
(115)\end{array}$ & $45(5175)$ & $50(5750)$ & 0 \\
\hline $\mathbf{N}^{\mathbf{0}} \mathbf{4}$ & $\mathrm{F}$ & $14 / 12 / 06$ & 8,80 & 0 & $2(176)$ & $\begin{array}{c}3 \\
(264)\end{array}$ & $63(5544)$ & $29(2552)$ & $3(264)$ \\
\hline $\mathbf{N}^{\mathbf{0}} \mathbf{5}$ & $\mathrm{M}$ & $14 / 12 / 06$ & 9,40 & 0 & 0 & $\begin{array}{c}11 \\
(1034)\end{array}$ & $71(6674)$ & $17(1598)$ & $1(94)$ \\
\hline
\end{tabular}

The mean Haematological values of the eritrograms and leucograms of the five animals of the Ammotraguslervia species studied are described in table 3, as well as the values of standard deviation and confidence interval (lower and upper limit).

Tabela 3:- Mean values of erythrogram and leukogram in Ammotraguslervia species $(\mathrm{n}=05)$

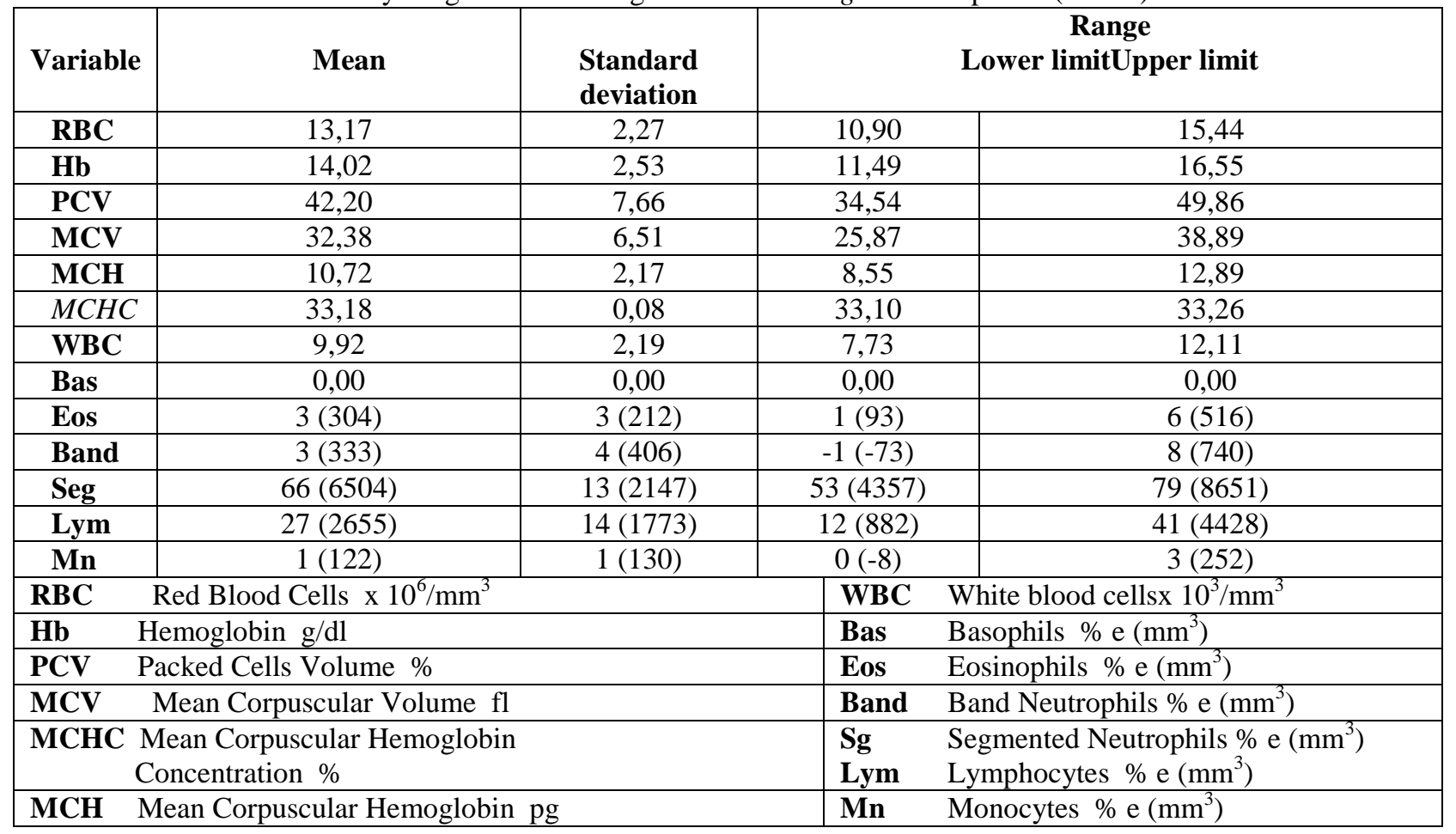

\section{Discussion:-}

It was possible to observe the existence of similarity between the results described in the literature for the Ammotraguslervia species, with few differences in relation to some variables for both the highest values of the parameters as to the lower values of the parameters. This is according to Peinado et al. (1999) that report be, the occurrence of these differences, probably due to the effects of climate, captivity, age, methodology used in the preparation of the samples and biological agents as was noted during the preparation of this species. 


\section{Eritrogram:-}

The results determined on this study show average values for Red blood cells (RBC) $\left(13.17 \times 10^{6} / \mathrm{mm}^{3}\right)$ were lower compared to the values reported by Tumbleson et al. (1970) and Huisman et al. (1968), respectively $15.27 \times 10^{6} /$ $\mathrm{mm}^{3}$ and $17.32 \times 10^{6} / \mathrm{mm}^{3}$.

The values for the limits of the confidence interval for Red Blood Cells (RBC) obtained in this work (10.90 to 15.44 $\mathrm{x} 10^{6} / \mathrm{mm}^{3}$ ) were lower than those found by Tumbleson et al. (1970) studying the blood samples of twenty-one copies of Ammotraguslervia (11.25 to $\left.23.42 \times 10^{6} \mathrm{~mm}^{3}\right)$, despite the average value $\left(13.17 \times 10^{6} / \mathrm{mm}^{3}\right) \mathrm{of} \mathrm{this} \mathrm{work}^{\circ}$ is within the confidence interval reported by the authors.

Haematological values obtained for Red Blood Cells (RBC) on this work for the Ammotraguslervia species present significant difference compared to haematological values described by Kitchen (1986) and Fowler (2003), both for the higher values and the lower values. The values found by the authors for the average and the limits of the confidence interval of RBC are much smaller $\left(5.8 \times 10^{6} / \mathrm{mm}^{3}-5.38\right.$ to $\left.6.2 \times 10^{6} / \mathrm{mm}^{3}\right)$ in relation to the same variables of this study $\left(13.17 \times 10^{6} / \mathrm{mm}^{3}-10.90\right.$ to $\left.15.44 \times 10^{6} / \mathrm{mm}^{3}\right)$, including the average value $\left(13.17 \times 10^{6} /\right.$ $\mathrm{mm}^{3}$ ) obtained in this work are within the limits of the confidence interval described by two authors (5.38 to $6.2 \mathrm{x}$ $\left.10^{6} / \mathrm{mm}^{3}\right)$.

For the hemoglobina values, the present research found (14, $02 \mathrm{~g} / \mathrm{dl})$, lower value compared to the values reported by Huisman et al. (1968) (15, $3 \mathrm{~g} / \mathrm{dl})$ and Tumbleson et al. (1970) who found $14.3 \mathrm{~g} / \mathrm{dl}$, for 21 animals, but within the limits of the confidence interval of the same (11.7 to $16.2 \mathrm{~g} / \mathrm{dl})$, established by Tumbleson et al. (1970). However, the value determined in this study was higher than the values found for Peinado et al. (1999), Wallach and Boever (1983), Kitchen (1986) and Fowler (2003).

The average Packed Cells Volume (PCV) of this work (42.20\%) was higher than the average PCV obtained by Tumbleson et al. (1970) in 21 animals of Ammotraguslervia (41.25\%) species, and than Wallach and Boever (1983), Kitchen (1986), Peinado et al. (1999) who studied six specimens, and Fowler (2003) and thanHuisman et al. (1968) in four animals. As to the limits of the confidence interval found on this work (34.54 to $49.86 \%$ ), the upper limit was above those found by Tumbleson et al. (1970) and Wallach and Boever (1983) which was 47.5\%, and for Kitchen (1986) and Fowler (2003) who found 37.2\%, as Peinado et al. (1999) which registered 46.0\%.

On the other hand, the value of the lower limit of the confidence interval of the PCV obtained by the work (34.54\%) is higher than that found by Tumbleson et al. (1970) and Wallach; Boever (1983) (32.3\%) and Peinado et al. (1999) which registered $22.5 \%$ and lower than the value reported by Kitchen (1986) and Fowler (2003) (35.7\%).

The same occurs with the values of the Mean Corpuscular Volume (MCV) obtained at this work which are higher (32.38 fl-25.87 to $38.89 \mathrm{fl})$ then the values reported by Huisman et al. (1968) (27.3 fl-18.1 to $34.9 \mathrm{fl})$, but the average value (32.38), is within the limits of the confidence interval described by the authors.

About the values obtained for Mean Corpuscular Hemoglobin $(\mathrm{MCH})$ on this work, the values of the averages and the lower limit of the confidence interval were higher (10.92 pg and $8.55 \mathrm{pg}$ ) than Tumbleson et al. (1970) and Wallach and Boever (1983) that were $9.6 \mathrm{pg}$ for the avarage and $6.2 \mathrm{pg}$ for the lower limit, and Peinado et al. (1999) which were, respectively, 9,79 pg and $8,51 \mathrm{pg}$. The value of the upper limit of the confidence interval found in our research (12.89 pg) was similar to Tumbleson et al. (1970), which featured $12.3 \mathrm{pg}$, but higher than Peinado et al. (1999) which was $10,7 \mathrm{pg}$.

Finally, analyzing the results obtained for the values of the Mean Corpuscular Hemoglobin Concentration (MCHC) by Tumbleson et al. (1970) for the average and for the upper limit of the confidence interval $(35.2 \%$ and $36.7 \%)$ and by Peinado et al. (1999), respectively (39.1\% and 44.8\%) that are higher than the values of this work $(33.18 \%$ and $33,26 \%)$ and the value for the lower limit of the confidence interval found by Tumbleson et al. (1970) (32.8\%) is lower than the value of the MCHC of this work (33.10\%), but within the limits of the confidence interval (32.8 to $36.7 \%$ ) reported by the same authors. However, Peinado et al. (1999) determined higher value (35.6) and, in this case, our value is outside the confidence interval. 


\section{Leucogram:-}

White blood cells:-

The value for the White blod cells (WBC) obtained for the upper limit of the confidence interval of five animals of Ammotraguslervia species $\left(9.92 \times 10^{3} / \mathrm{mm}^{3}\right.$ and $\left.12.11 \times 103 / \mathrm{mm}^{3}\right)$ on this study were below the values reported by Tumbleson et al. (1970), for twenty-one animals of Ammotraguslervia species, that was $11.2 \times 10^{3} / \mathrm{mm}^{3}$ for average and $17.0 \times 10^{3}$ to $5.21 / \mathrm{mm}^{3}$ for confidence interval, lower, too, that was published by Kitchen (1986) and Fowler (2003) $\left(92 \times 10^{3} / \mathrm{mm}^{3} 13.2\right.$ and $\left.14.8 \times 10^{3} / \mathrm{mm}^{3}\right)$, but were higher when compared with the findings of Peinado et al. (1999) working with six animals $\left(3.70 \times 10^{3} / \mathrm{mm}^{3}\right.$ and $\left.6.0 \times 10^{3} / \mathrm{mm}^{3}\right)$.

Although the value obtained for the lower limit $\left(7.73 \times 10^{3} / \mathrm{mm}^{3}\right)$ of the confidence interval, in this work is higher than the value obtained by Tumbleson et al. (1970) to the lower limit $\left(5.21 \times 10^{3} / \mathrm{mm}^{3}\right)$ and Peinado et al. (1999) $\left(1.85 \times 10^{3} / \mathrm{mm}^{3}\right)$, but lower than the values quoted by Kitchen (1986) and Fowler (2003) that was $11.6 \times 10^{3} / \mathrm{mm}^{3}$.

\section{Differential leukocyte count:-}

During the study of the differential leukocyte counts for Ammotraguslervia species values obtained for Segmented Neutrophils were average of $66 \%$ and for its limits of the confidence interval 53\% to 79\%, values similar to those described by the authors Peinado et al. (1999), Tumbleson et al. (1970), Wallach;Boever (1983), Kitchen (1986) and Fowler (2003).

The study on the values of the Band Neutrophils for Ammotraguslervia species in five animals evaluated in this research had as 3\% average and the limits of the confidence interval of 1 to $8 \%$. Peinado et al. (1999), Tumbleson et al. (1970), Wallach;Boever (1983), Kitchen (1986) and Fowler (2003), in its publications, did not report any value for the Band Neutrophils.

The values described by the authors Peinado et al. (1999), Tumbleson et al. (1970), Wallach; Boever (1983), Kitchen (1986) and Fowler (2003) for Lymphocytes to Ammotraguslervia species are quite similar to the values obtained for this variable in this study (27\%). However, when we compare the results of the values of the literature consulted, we found that the values of Peinado et al. (1999) are higher (43.45\%) than the values of others.

The results obtained for Monocytes to Ammotraguslervia species of five animals in this work for the average (1\%) and for the limits of the confidence interval (0-3\%) are similar to values reported by Peinado et al. (1999), Tumbleson et al. (1970), Wallach; Boever (1983) although Kitchen (1986) and Fowler (2003) did not report any value for this variable in their work to the same species.

The values determined for Eosinophils to Ammotraguslervia species, by Peinado et al. (1999), Tumbleson et al. (1970), Wallach; Boever (1983), Kitchen (1986) and Fowler (2003) are similar to the values found in this work for the average (3\%) and to the limits of the confidence interval (1 to 6\%) for the five animals of Ammotraguslervia species in this work, having only just above the upper limit of the values described by the authors.

The result given to the values of Basophils to Ammotraguslervia species in this work was 0\%, which is consistent with the results reported to the values of Basophils by Peinado et al. (1999), Tumbleson et al. (1970), Wallach; Boever (1983), Kitchen (1986) and Fowler (2003) did not determined any value for this variable.

\section{Conclusions:-}

The results obtained in this study are likely to minimize the difficulties faced by Veterinarians who specialize in wildlife, and technicians who work in Zoological Parks. The continuation of research not only with haematological parameters, but also with biochemical, enzimological and genetic studies that in future will provide subsidies for a better evaluation of the sick animals of this Ammotraguslervia species, particularly regarding the vulnerabilities of the species to diseases that before had no contact, including zoonoses, that concerns of the human population and public health. 


\section{References:-}

1. Boever, W. J.(1986): Artiodactylid Identification. In M. E. Fowler, Zoo \& Wild Animal Medicine, v.2, Philadelphia, W. B. Saunders Company: 940-945.

2. Cassinello, J. (1998): Ammotraguslervia: review on systematics, biology, ecology and distribution. In AnnalesZoologiciFennici (pp. 149-162). Finnish Zoological and Botanical Publishing Board.

3. CITES - Convention on International Trade in Endangered Species of Wild Fauna and Flora - Appendix II. [cited 28 December 2016]. Available from: www.cites.org.

4. Coles E. H. (1984): PatologiaClínicaVeterinária. V.3, São Paulo-SP, Manole, pp. 566

5. Fowler, M. E. (2003): Sheep, Goats, Goatlike Animals. In Fowler, M. E., and Miller, R. E. Zoo and Wild Animal Medicine, v.5, St. Louis, Saunders: 675-683.

6. Huisman, T. H. J., Dasher, G. A., Moretz, W. H., Dozy, A. M., Wilson, J. B., Vliet, G. (1968): Studies of Haemoglobin Types in Barbary Sheep (Ammotraguslervia). Biochemical Journal, 107:745-751.

7. IUCN The IUCN Red List of Threatened Species. Version 2016-3. [cited 28 December 2016].Available from: <www.iucnredlist.org>.

8. Jessup, D. A. (1999): Capture and Handling of Mountain Sheep and Goats. In M. E Fowler, R. E. Miller, Zoo \& Wild Animal Medicine (Current Therapy), v. 4, Philadelphia, W. B. Saunders Company: pp. 681-687.

9. Kitchen, H. (1986): Hematological Values and Blood Chemistries for a Variety of Artiodactylis. In Fowler, M. E. Zoo and Wild Medicine, v.2, Philadelphia, W. B. Saunders Company: pp. 1003-1017.

10. Nowak, R. M. (1999):Walker`s Mammals of the World. V.6,Baltimore, Maryland, EUA, The Johns Hopkins University Press, pp.1712.

11. Peinado, V. I.; Celdran, J. F.; Palomeque, J. (1999): Basic Hematological Values in Some Wild Ruminants in Captivity. Comp. Biochem. Physiol., Part A, 124(2):199-203.

12. Rullier, J. andParodi, A. (1968): Laboratoire et diagnostic en MédicineVétérinaire. Paris, VigotFères, pp.712.

13. Schalm, O. W., Jain, N. C., Carrol, E. J. (1975): Veterinary Hematology, v.3.Philadelphia, Lea \&Febiger, pp.1221.

14. Shackleton, D. M. (1997): The IUCN/SSC caprine specialist group. Wild Sheep and Goats and their Relatives. Status Survey and Action Plan for Caprine(Gland, Switzerland and Cambrige, UK:IUCN.

15. Tibbo, M., Jibril, Y., Woldemeskel, M., Dano, F., Aragaw, K., Rege, J. E. O. (2004): Factors affectting hematological profiles in three Ethiopian Indigenous goat breeds. J. Appl. Res. Vet. Med., 2(4): $297-309$.

16. Tumbleson, M. E., Middleton, G. G., Wallach, J. D. (1970): Serum Biochemic and Hematologic Parameters of Adult Aoudads (Ammotraguslervia) in Captivity. Lab. Anim. Sci., 20(2):242-245.

17. Wallach, J. D., Boever, W. J. (1983): Diseases of Exotic Animals: Medical and Surgical Management. Philadelphia, W. B. Saunders Company, pp.1159.

18. Wilson, D. E., Reeder, D. M. (2005): Mammals Species of the World: a Taxonomic and Geographic Reference. 3, Baltimore, Maryland,Johns Hopkins University Press, pp. 2142. 